\title{
Arquitetura \\ e romance \\ em Antonio di \\ Pietro Averlino
}

\section{Vitor Murtinho*}

Resumo Antonio Averlino, conhecido como il Filarete, é o autor do livro Trattato di Architettura. Aqui aborda-se o facto de este importante texto renascentista, um dos primeiros com ilustrações, tendo como pretexto a disciplina da arquitetura, corresponde a uma obra com uma forte componente de ficção, podendo mesmo ser considerado um romance. É sobre esta dualidade do livro de Filarete que este artigo trata.

Palavras-chave: Filarete, arquitetura, romance.

\section{Arquitectura y novela en Antonio di Pietro Averlino}

Resumen Antonio Averlino, conocido como il Filarete, es el autor del libro Trattato di Architettura. Aquí abordamos el hecho de que este importante texto renacentista, uno de los primeros con ilustraciones basado en la disciplina de la arquitectura, corresponde a una obra con un fuerte componente de ficción, que puede considerarse una novela. Este artículo trata sobre esta dualidad del libro de Filarete.

Palabras clave: Filarete, arquitectura, novela.

\section{Architecture and novel in Antonio di Pietro Averlino}

Abstract Antonio Averlino, known as il Filarete, is the author of the book Trattato di Architettura. Here we approach the fact that this important Renaissance text, one of the first with illustrations, with central theme of the discipline of architecture, corresponds to a work with a strong fiction component, which can be considered a novel. The subject of this article addresses this duality of Filarete's book.

Keywords: Filarete, architecture, novel. 
A tonio di Pietro Averlino (c.1400-69), era - segundo o próprio - um amante da virtude. Ao adotar para si o nome de Filarete, que objetivamente corresponde em grego a alguém que pratica o bem, estaria - talvez no seu espírito - a apaziguar uma história antiga que o fez compulsivamente abandonar a cidade de Roma no seguimento da grave acusação de tentativa roubo da relíquia da cabeça de São João Baptista que atualmente se encontra exposta numa capela lateral da Igreja de San Silvestro in Capite. Sabendo-se que este artista era um protegido do Papa Eugénio IV, por quem tinha sido encarregado de produzir o importante encargo das portas - em bronze - para a entrada da antiga Basílica de S. Pedro, é admissível que esta acusação tenha aparecido em processo de ajuste de contas, dado a coincidência com o óbito do Sumo Pontífice (MURTINHO, 2015, pp 230-231). Apesar desta incriminação ter merecido o perdão papal, Filarete foi impedido de concluir a obra do túmulo do Cardeal de Portugal, D. Antão Martins de Chaves (falecido em 1447), na Igreja de San Giovanni in Laterano, em Roma. Apesar de diligências da Senhoria de Florença (MUNTZ, 1883, p. 33), o trabalho seria realizado por Isaia da Pisa - que havia sido colaborador de Donatello e cujo irmão, Simone Ghini, trabalhou com Filarete em S. Pedro (CAVALLERO, 1990, p. 132). Após a saída tempestiva de Roma, Averlino, terá rumado a norte, sendo conhecida a passagem pela Toscana (Florença e Arezzo), pela Emília-Romanha (Rimini e Piacenza), pelo Véneto (Veneza, Pádua e Bassano del Grappa) e pela Lombardia (Lodi e Mântua), antes da sua fixação em Milão, a partir de 1451, ao serviço de Francesco Sforza (SALMI, 1973, p. XI).

Pelo que se sabe, Averlino parece ter tido uma enorme generosidade intelectual e profissional, mas as circunstâncias históricas fizeram com que a sua meritocracia não tenha sido, à sua época, justamente reconhecida. Com uma obra artística de dimensão e impacto muito limitados, é natural que ele visse como possibilidade de fazer prova perene das suas capacidades o desenvolvimento de um peculiar trabalho baseado em escrita e suportado por desenhos ilustrativos. Se no início da sua atividade, Averlino, é claramente um homem relacionado com as artes escultóricas, na sua fase mais madura, já ao serviço no ducado de Milão, assume-se como engenheiro ou como arquiteto, dependendo dos contextos e das circunstâncias. Em qualquer das designações, a utilidade do termo servirá certamente como modo de garantir autoridade, de satisfazer uma exigência de gestão do estaleiro de obra ou de certificar a capacidade de manuseamento dos instrumentos que possibilitam a conceção da arquitetura. Na escrita, apesar de o fazer num modo titubeante e pouco esclarecedor, deixou legado - importante - que atesta a sua tentação literária, constituindo uma espécie de testemunho do seu pensamento, da sua competência construtiva e da sua

* Vitor Murtinho é Arquiteto, Centro de Estudos Sociais / Departamento de Arquitectura Universidade de Coimbra, ORCID $<$ https://orcid.org/0000-00028956-7382> capacidade para a efabulação.

Hoje, uma boa parte da vivência e do legado filaretiano são convenientemente estruturados a partir do seu livro, o denominado Tratatto di Architettura, que no seu seio mistura o dogma religioso e a laicidade, que coloca no mesmo plano o facto 
histórico e a ficção. Este texto, muito relevante para a história da arquitetura, é uma mistura "esquisita" entre fábula, conhecimento e acontecimento, desenvolvendo-se narrativamente em situação abundante de diálogo que tanto questiona a natureza das coisas como, a pretexto da construção de uma cidade idealizada com o nome de Sforzinda, é o motivo persuasor para se ensaiar uma lição sobre o modo de fazer e de encarar a arquitetura. A fundação daquela cidade constitui o centro temático da livro e no modo como a escrito evolui, surge notoriamente como uma exposição romanceada, correspondendo a uma intrincada conjugação de efabulações, associadas a factos reais que certamente ajudam a credibilizar os conteúdos, dando densidade à história. Este escrito, com uma composição predominantemente narrativa, conjugado com vários diálogos, procede ao cruzamento de elementos antigos com acontecimentos e factos seus contemporâneos, aproximando a estrutura do texto a algo que se assemelha muito ao caráter de um romance (SCHULTZ, 1967, p. 472).

\section{A escrita da arte e da arquitetura}

O desenvolvimento de escritos que no seu seio congreguem um máximo de informação diversificada, fazendo síntese ou expressando um ponto de situação sobre o estado do conhecimento, foi algo que pode ser detetável - mesmo que de modo ainda pouco sistematizado - desde tempos bastante antigos. Tanto - por exemplo - Aristóteles como Plínio, o Velho, produziram textos tendo como estratégia o englobamento de conhecimento sobre temas por eles estudados. No caso do filósofo grego, o que chegou até ao tempo presente é sobretudo uma sombra daquilo que poderá ter sido o verdadeiro conhecimento obtido por Aristóteles pois ao tratarem-se de textos incompletos, não permitem perceber - como bem definiu André Cresson - se estamos perante o conjunto de elementos que permitiriam a construção de um distinto monumento ou se se tratam das ruínas de um esplendoroso edifício que entretanto se desmoronou (CRESSON, 1988, p. 15). Seja qual for o ponto de vista, o espírito enciclopédico, demonstrado por este aluno de Platão, aborda inúmeras questões que se espraiam entre problemas de natureza física a assuntos de metafísica. No caso do escritor romano, Plínio o Velho, os resultados chegaram de modo mais sistematizado, anunciando melhor organização ou pelo menos maior sorte na forma como nos chegou o seu pensamento. A sua Historia naturalis corresponde a um compêndio sobre ciência antiga, composto por trinta e sete volumes, fazendo síntese de um saber de época, essencialmente extraído de outra literatura. Talvez por essa circunstância - e porque a maior parte das suas fontes se encontra perdida - a sua obra tanto pode constituir um grande reservatório como um túmulo de todo um saber antigo (SCHLOSSER, 1984, p. 45).

Com o tempo, redobram-se os esforços de condensação do conhecimento, mesmo que esta tarefa possa ter contornos incomportáveis para um único indivíduo. Apesar disso, Santo Isidoro de Sevilha, por volta de 630 redigiu em latim o seu Etymologiae, plasmado por 20 livros e 448 capítulos com citações extraídas pelo próprio, constituindo um notável testemunho de erudição e de informação. Mas, seria Vicente de Beauvais que, em 1260, ao publicar o seu Speculum majus, repartido por 80 volumes e 9885 capítulos, exprimindo uma clara situação de ordem, constituía-se como uma corrente, com elos sistematicamente posicionados, ofereceu uma pioneira amplitude de conhecimento (ECO, 2014, p. 33). 
Em paridade à constituição de corpos estruturados de textos enunciando sínteses de saberes globais, foi natural que no âmbito das especificidades também houvesse espaço para escritas apuradas, exprimindo conhecimentos adquiridos ou transposições de resultados autorais. No que se considera a reflexão em torno da arte, são inúmeras as referências na antiguidade que aparecem, normalmente, como parte integrante de textos mais gerais. Se Platão ou Aristóteles têm sido recursivamente fontes citadas para caracterizar determinadas formalizações, a História Natural de Plínio tem sido um recurso abundante para a consulta sobre o saber antigo. No caso específico da arte, Plínio dedica-lhe sequencialmente três dos seus livros, do XXXIV ao XXXVI.

Foi com Vitrúvio que apareceria um texto congruente sobre arquitetura e que, curiosamente, foi uma das fontes a que recorreu Plínio para a construção da sua história natural. Com datação por volta do século I a. C, os Dez Livros sobre Arquitetura, correspondem supostamente a uma compilação que salvaguarda um conjunto vasto de informação em torno da arte de edificar, englobando urbanismo, construção, decoração e engenharia, mas também, sobre hidráulica, gnomónica e mecânica (MACIEL, 2006, pp. 10 a 12). Este texto que sintetiza uma boa parte do saber construtivo da época, terá tido como base toda uma documentação que a erosão dos tempos não terá permitido preservar. Nesse sentido, no modo como os assuntos são dissecados, tentando fazer súmula daquilo que pode ser útil para o exercício profissional, poderemos dizer que este se assemelha a um verdadeiro tratado. Este é um texto que historicamente é referido e depois abandonado segundo a necessidade dos autores, até que, no contexto do século $X V$, passou a ter uma desmesurada celebridade, aparecendo conotado como um texto fundador (CERVERA VERA, 1978). Ao humanista Poggio Bracciolini, deve-se sobretudo a circunstância de ter descoberto na biblioteca do mosteiro beneditino de Saint Gaal, na Suíça, em 1414, uma importante edição latina de Vitrúvio, transformando esse facto num acontecimento que adicionado à vontade de perscrutação das formas e da literatura clássicas, favoreceu o mito da criação de um momento inaugural (MCEWEN, 2003, pp. 1-2).

Um outro "livro", elaborado no período medieval, merece particular destaque é o designado caderno de viagens de Villard de Honnecourt e que corresponde a um conjunto não sistematizado de apontamentos, suportados por um interessante complemento desenhado, ajudando a perceber o ambiente conceptual relacionado com as obras de construção civil. Com uma dimensão correspondente a 33 fólios (BARNES, 2009, pp. 267 sgg.) e apesar de ter tido, temporalmente, pouco impacto, a atenção mais recente a este manuscrito tem ajudado a um melhor conhecimento das problemáticas que envolviam a arquitetura gótica em França. A natureza das descrições, designadamente alguns procedimentos geométricos e a enumeração visual de diversos instrumentos ou aparatos de obra, tornaram este documento muito relevante para efeitos da compreensão de competências e de condições técnicas medievais (BECHMANN, 1991).

No caso da publicação de Vitrúvio, os horizontes, as dinâmicas e o alcance foram diferentes. Pela sua natureza, o texto do arquiteto romano, era propiciador a estimular a imaginação e a criar no seu leitor a necessidade de imagens que esclarecessem melhor o conteúdo descrito. Nesse sentido, rapidamente as sucessivas reedições, passaram a inserir registos desenhados que possibilitassem tanto um maior rigor descritivo. No entanto e no tocante às questões relacionadas com as particularidades das designadas 
ordens arquitetónicas, bem como em situações de clarificações tipológicas dos edifícios, rapidamente se verificou ser o Tratado de Arquitetura um instrumento deveras limitado, dando lugar a que outros autores elaborassem propostas consistentes que ofereciam melhores soluções, recorrendo à estruturação por temas e a eficazes ilustrações que respeitando uma categorização por elementos arquitetónicos possibilitavam uma formação mais segura aos diversos intervenientes na matéria (WIEBSON, 1988, p. 14).

Na caracterização de um percurso temporal no que concerne à teorização ou abordagem sobre a arte da arquitetura, o De re aedificatoria de Leon Batista Alberti (ALBERTI, 2011), constitui um aparato relevante, deixando marca distintiva quanto ao seu conteúdo. Segundo parece, teria existido um propósito inicial relacionada com uma análise do texto vitruviano, mas que rapidamente se transformou num projeto autónomo, vigoroso, que deixou lastro para alavancar todo uma teoria e uma produção arquitetónica. No caso específico, pode-se admitir que o interesse sobre a arte de manipulação do espaço possa ter aparecido mesmo ainda antes de experiência notável de projeto. Sendo Alberti um irrepreensível intelectual, é natural que mesmo que tivesse existido previamente um encargo relacionado com a arte edificatória, a sua natureza daria ímpeto sensível para o estudo apurado do tema, permitindo-lhe obter um desempenho certo e seguro. A teoria e a prática podem designar uma espécie de contraponto, assumindo-se tanto como competências díspares, como situações complementares, que de algum modo se auxiliam mutuamente. Esta ordem argumentativa dará azo a uma multiplicidade de análises, muito motivadas, certamente, por interesses específicos ou conjunturais, onde cada ser fará a apologia da sua particularidade tentando daí extrair norma convincente. Na definição de ofertas ou no desenvolvimento de propostas credíveis que sublimam a temática arquitetónica, encontramos sequencialmente uma literatura como a de Antonio Averlino, Sebastiano Serlio, Andrea Palladio, Giacomo Vignola ou Vincenzo Scamozzi. Todos eles com provas firmadas na prática disciplinar e todos precisando do recurso ilustrativo para complementar e valorizar o seu discurso escrito. Todos eles sublimando a grandeza de uma disciplina que requer vistas largas e horizontes complementados por conhecimentos geométricos, sensibilidade estética e amplo domínio da ciência construtiva.

Sabemos hoje que o interesse recaído sobre a publicação de Vitrúvio e alguma manualística como o De re aedificatoria de Alberti - depois do hercúleo trabalho arquitetónico desenvolvido por Filippo Brunelleschi -, propiciaram uma atmosfera transformativa, induzindo a alterações processuais e conceptuais. Entre estas é de destacar o processo translacional do traçado gótico através do compasso para uma versão mais intelectualizada, muito apoiada em princípios e normas de proporcionalidade e de ordem (SCHLOSSER, 1984, p. 72). A arte edificatória de Alberti, pressupõe um conhecimento preciso dos conteúdos da obra vitruviana, mas corresponde a um aprofundamento de temas, respetiva atualização e tratamento com muito maior amplitude, oferecendo um resultado muito mais rigoroso, refrescante e consistente, permitindo uma visão mais completa e integrada da realidade clássica (WIEBSON, 1988, pp. 11-12).

Curiosamente na definição de um quadro temporal, quiseram as circunstâncias e os desígnios editoriais que o texto albertiano fosse publicado em 1485, um ano antes ainda da edição príncipe de Vitrúvio, mas numa data com uma projeção superior a mais de uma década depois da morte do seu autor. Este facto confere a estes dois 
textos o estatuto de primeiros na história da arquitetura a serem impressos e com disseminação alargada. Inevitavelmente, com a valorização do processo de projeto enquanto fator primordial antecedente à produção arquitetónica, foi-se tornando evidente que num mesmo cenário estavam a convergir questões de índole conceptual e situações do foro pragmático. Qualquer elaboração prévia que congregasse a vontade de concretização por recurso a processo formalizado através de elementos gráficos, a escala determinada, organizados segundo vistas e projeções planares, tornou-se o sistema congruente para mediar o mundo da mente que concebe e o do artífice que executa. No mundo da produção de arquitetura, em parte devido à disseminação da imprensa, no engenho do espaço, passa a ser eficaz o acesso direto a fontes e a tratadística formativa como auxiliar de projeto. A componente unitário do desenho, supondo domínio de linguagem e necessitando de apurado apetrecho de complexas relações formais e proporcionais, ligado a uma bagagem de conhecimento das diferentes dinâmicas construtivas, da autoridade de gestão de um estaleiro, da sensibilidade ao potencial estático dos edifícios, tornam as práticas uma questão muito complexa e exigente. Esta redoma, com enorme responsabilidade, abriu uma frente que gerou uma pressão no sentido da necessidade de informação escrita que congregasse sistematicamente súmulas de conhecimento. Se olharmos estritamente para as motivações e as lógicas dos tratados sobre arquitetura de Alberti e de Filarete, iremos encontrar no primeiro a construção de um discurso que será posteriormente legitimado por uma prática, enquanto no segundo temos um texto que assenta numa prática que por sua vez ajudou a dar argumento e consistência à escrita.

\section{Filarete: arquiteto e romancista}

Para a história da arquitetura, depois do Tratado de Arquitetura de Vitrúvio, do De re aedificatoria de Alberti, o terceiro texto disciplinar foi o denominado Trattato di Architettura de Filarete. Este texto, desenvolvido durante a estada do arquiteto ao serviço de Sforza, apresenta características muito distintas dos outros tratados referidos. Uma segunda versão, elaborada em data posterior e decorrente da saída de Filarete do ducado de Milão, tem com principal diferença a adição de mais um livro - o vigésimo quinto - dedicado a Piero Cosimo de' Medici, cujo conteúdo enaltece a cidade de Florença e a obra aí desenvolvida. Os dois tratados filaretianos correspondem genericamente ao mesmo texto, adquirindo alguma relevância a questão de diferentes dedicatórias quando avaliadas numa lógica de um primeiro insucesso patronal, que pretende ser corrigido com a exploração de um outro potencial patrocínio, mas que não terá sido corporizado. Como reconhecimento do valor dado ao tratado filaretiano, na década de oitenta do século XV, foi feita uma edição em latim, mandada fazer por Mattia Corvino, Re d'Ungheria. (FARBAKY, 2003, p.122).

O Tratatto de Architettura filaretiano, para além do seu posicionamento histórico na relação dos diferentes textos sobre esta arte, adquire peculiar importância devido à sua estrutura narrativa, a que acresce o facto de ser o primeiro texto do género, escrito em língua vulgar. Quer o De re aedificatoria quer o tratado vitruviano nas suas primeiras edições eram em latim, tal como acontecia com a maior parte da literatura daquela época. Mesmo que esta particularidade linguística decorra de uma insuficiência de Averlino perante a sua dificuldade com o latim, o resultado transforma este texto em pioneiro na divulgação de conteúdos de arquitetura para um público mais vasto. Esta será uma via que, mais tarde, Francesco di Giorgio Martini também escolherá, utilizando 
uma linguagem acessível, devidamente complementada por aparato gráfico que ajudará a consolidar o caráter prescritivo dos seus Trattati di Architettura, ingegneria e arte militare. Esta última obra, que foi por várias vezes escrita e reescrita entre 1475 e 1495, num misto de guia profissional e preceituário teórico, coloca inevitavelmente a disciplina arquitetónica num contexto muito científico, englobando questões de inventividade, de competência construtiva e de conhecimento matemático, sobretudo de geometria e de aritmética (MERRIL, 2013, p. 1). Curiosamente, são também estas as questões que de um modo mais comedido e menos organizado, Filarete se propõe antecipadamente abordar. Sob o ponto de vista de formalização e de organização, estamos em presença de duas abordagens totalmente distintas. Se com Francesco di Giorgio a argumentação respeita uma estrutura que pretende corresponder a um guião, assumindo-se como um tratado, o texto de Filarete é uma amálgama de argumentos e de experiências que não se consegue definir como sendo uma publicação homogénea e com assuntos encadeados. Apesar de, Averlino, recorrer a autoridades como a de Vitrúvio ou de Alberti, nem por isso a natureza expressiva dos seus raciocínios chegam para conferir substância e robustez aos argumentos. Em ambos os casos, aquilo que transparece é que estas fontes seriam mais um recurso que havia sido manuseado ou mesmo estudado, não se percebendo se no preciso momento de passagem a escrito do seu texto sobre arquitetura, eram algo que Ihe estivessem acessíveis. Todavia, não pode ser negligenciável a circunstância de numa relação de livros pertencentes a Filippo Maria Visconti - realizada em 1426 -, constar uma edição manuscrita completa do tratado vitruviano (PELLEGRIN, 1955, p. 130). Já no caso de Alberti, as diversas passagens em que este é referido por Filarete, tem muito mais a ver com o seu trabalho enquanto autor que domina o desenho e a perspetiva, não deixando transparecer que houvesse um conhecimento suficiente do De re aedificatoria. Se o texto filaretiano trata de assuntos relacionados com a arquitetura, a sua concretização em nada se assemelha, sob o ponto de vista canónico, a um tratado. Para isso, era preciso que de modo sistematizado tratasse teorias, regras, métodos e práticas, permitindo definir horizontes orientativos para o exercício e para a análise da arquitetura. Aquilo que se verifica como existente no texto de Filarete é a criação de um conto que mescla dados reais e muita efabulação, possibilitando a construção de argumentos que têm como principal objetivo a tentativa de afirmação de um praticante num contexto que na maior parte das vezes lhe era desfavorável e muito pouco recetivo a um modo de fazer, já consolidado na Toscana, mas que dava os primeiros passos no ducado de Milão. A análise dos desenhos que acompanham o texto de Averlino, não deixa a segurança suficiente para que se forme uma opinião no sentido de que a natureza do discurso fosse consentânea com o primazia de uma prática lapidar.

Para a perceção do enquadramento e do valor da obra escrita filaretiana é particularmente relevante a análise feita por Julius von Schlosser. Na sua obra magna A Literatura Artística, ao abordar os teóricos da primeira Renascença proceda a uma separação do trabalho de Alberti relativamente aos outros artistas e intelectuais, que agrupa em produtores de uma pura teoria e os que apelida de românticos (SCHLOSSER, 1984, pp. 153, 163 e 172). Esta metodologia de hierarquização tripartida permite uma melhor e mais informada leitura de trabalhos que na sua génese e impacto são bastante distintos. Neste contexto, o que se torna particularmente relevante é a circunstância de Schlosser considerar o tratado filaretiano como uma publicação com veste romântica. Nesse sentido, o seu conteúdo é tratado de modo distinto da literatura mais técnica ou de cariz mais teorizado e agrupado ao livro atribuído a Francesco Colonna, O Sonho de 
Polifilo(SCHLOSSER, 1984, pp. 163-168). Esta estratégia é também corporizada numa descrição que considera, tratar-se de um diálogo, transformando o discurso num texto instrutivo, jogando o narrador um papel de professor toscano que ensina um conjunto de boas práticas e de bom gosto. Neste último aspeto, quase se poderiam direcionar os conteúdos para um contexto de índole didática, mas se atentarmos à metodologia processada, este recurso serve o propósito de sublimação de conhecimento do autor, principalmente num contexto em que esta estratégia se torna relevante em termos do seu reconhecimento cultural e profissional.

Na realidade, o recurso a uma escrita efabulada, imageticamente criativa, justifica toda uma criação novelística que em múltiplos aspetos potenciam a assunção de alguma teatralidade narrativa. Na prática uma parte da narrativa do texto filaretiano é assente num pressuposto pedagógico e de educação. Esta dicotomia entre aprendizagem e ensino, muito mais do que um enredo narrativo é, inquestionavelmente, um eficiente meio para a sobrevalorização de uma das personagens - que acumula o papel de narrador -, sobretudo pela sua riqueza de conhecimentos e do seu reconhecimento como indivíduo apto e competente para o fazer. Os ritmos, as ações, os percalços e os acontecimentos presentes no livro, inúmeras vezes apoteóticos, com magia e predestinação à mistura, constituem um corolário expressivo de um tipo de mentalidade, mas também geram o testemunho necessário de uma estada que pareceu no mundo real estar muito condenada ao insucesso. Se no início as expectativas para Filarete, poderiam ter sido grandes, uma atmosfera lombarda conservadora e bastante reativa à cultura toscana muito rapidamente serviu para refrear os ímpetos e condicionar tentativas de práticas mais modernas. Literariamente, não existindo matéria que constituísse originalidade suficiente para a produção de tratado ou manual técnico, a opção por uma escrita ficcionada pode ter sido o melhor meio para deixar registo e memória de passagem pelo ducado de Milão. Todo o texto, tal como se apresenta, articula-se entre um futuro que se quer promissor e a nostalgia do passado cuja narrativa é sobretudo mais emulada do que conhecida (PEDRAZA, 1990, p. 19). Pelo que, a assunção de uma descrição muito efabulada, que usa como tempero uma promiscuidade entre realidade e ficção, recorre sistematicamente a suposições fantásticas que nada têm de arqueológico, mas que avivam e tornam mais acutilante a sublimação de um putativo passado que serve somente para a consagração daquele presente.

Como reforço de verosimilhança, uma boa parte da narrativa é desenvolvida segundo uma lógica de explicitação de acontecimentos que se assemelha a um diário muito estruturado em discursos dialogados, o que coloca este texto num quadro autobiográfico, mas com uma densidade muito ficcionada. Esta estratégia é materializada através de uma escrita que não se oferece como particularmente elaborada, que muitas vezes se aproxima das formas orais, mas incorporando uma estrutura que, em parte, se assemelha aos estratagemas utilizados pelos contadores de histórias. Toda esta densidade e diversidade, mesclando acontecimentos reais com ocorrências fantásticas pretende cativar a atenção dos seus leitores, oferecendo diversidade e amplitude de conteúdos. Destinado a um público que era expectante que fosse letrado, pelo que se torna razoável a descrição de algumas situações quotidianas ou de excecionalidade que envolvem os circuitos mais cultos ou relacionados com a ambiência mais palaciana. Como ilustração deste aspeto basta referir a descrição do banquete, logo no início do livro - livro I-, onde Filarete é tratado com alguma deferência e cortesia, adquirindo algum protagonismo na cena, como também - livro $I V$ - a cerimónia da colocação 
Figura 1: Implantação da cidade de Sforzinda. Fonte: Filarete, Trattato di Architettura, Libro II, folio $11 \mathrm{v}$. da primeira pedra de Sforzinda onde numa placa de mármore deveria ser gravado o ano do acontecimento, acrescido da inscrição do nome do duque, do Sumo Pontífice e do arquiteto (FILARETE, 1972). Ao longo do discurso filaretiano é notoriamente percetível um processo intencional de valorização do trabalho e do ofício dos arquitetos em termos gerais e o seu em particular (PEDRAZA, 1990, p. 24). Sendo este um dos grandes ganhos do Renascimento, esta situação de dignificação do trabalho artístico e da seu reconhecimento - mesmo em termos pecuniários - é uma evidência que se encontra narrada de modo consistente ao longo de todo a enredo construído por Averlino. Tal como houvera feito Vitrúvio, Filarete, procede a uma inequívoca valoração do estatuto social do arquiteto, afastando-o dos grupos mais relacionados com o operariado e incluindo-o numa redoma que the confere um vínculo de intelectualidade e de cientificidade.

De modo muito sintético poderíamos referir que o designado Tratado de Arquitetura, ou o architettonico libro como Filarete gostava de lhe chamar, descreve o processo de construção de uma grande cidade denominada de Sforzinda (FILARETE, 1972, p. 7). Trata-se de uma cidade construída de raiz segundo um modelo organizativo inovador, que deriva para fazer prova de capacidade imaginativa e de competência para a sua concretização. Será plausível que nesta demonstração de proficuidade urbanística e tendo em linha de conta toda a contextualização que conduz quer à escolha do local, quer às características do espaço proposto, Averlino tenha em mente o trabalho desenvolvido por Dinócrates e que aparece convenientemente referido no texto vitruviano. Revisitando Vitrúvio, podemos encontrar a descrição de um sonho visionário oferecido a Alexandre o Magno, correspondendo a uma utopia transformativa - com matriz anatómica - do monte Athos, na Grécia, que apesar de oferecer proteção amuralhada e água potável abundante tinha a fragilidade de não possuir campos férteis suficientes (VITRÚVIO, 2006, pp. 69-70).

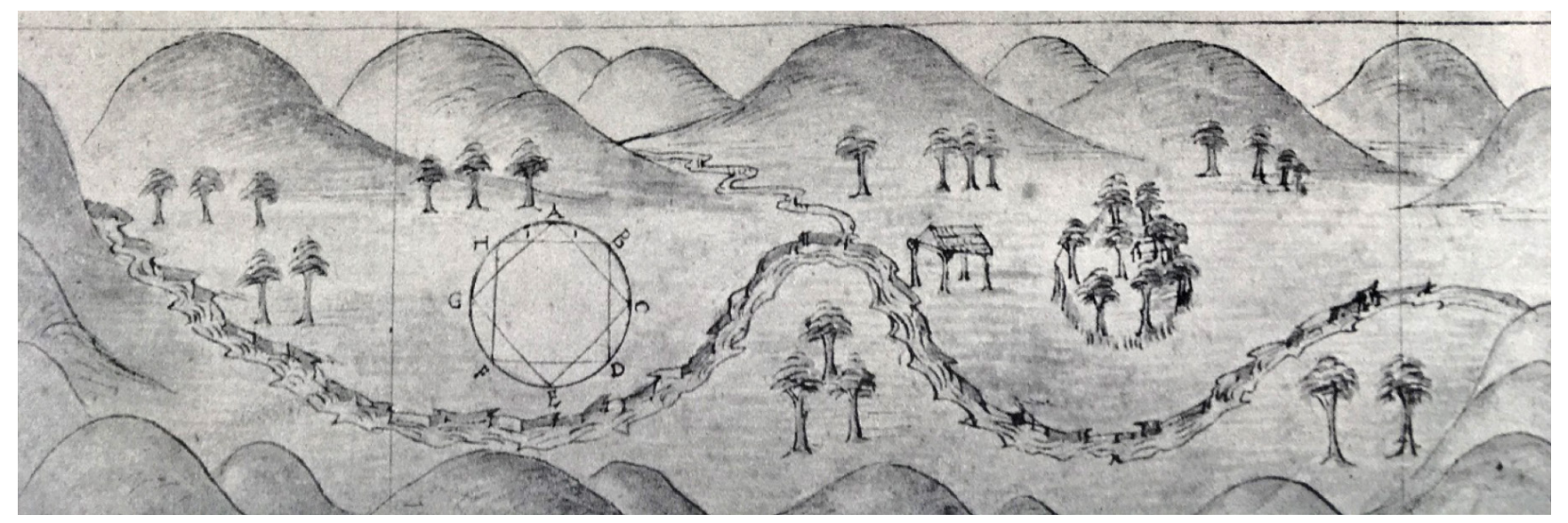


Figura 2: Desenho geométrico do traçado de Sforzinda. Fonte: Filarete, Trattato di Architettura, Libro VI, folio 43 r.

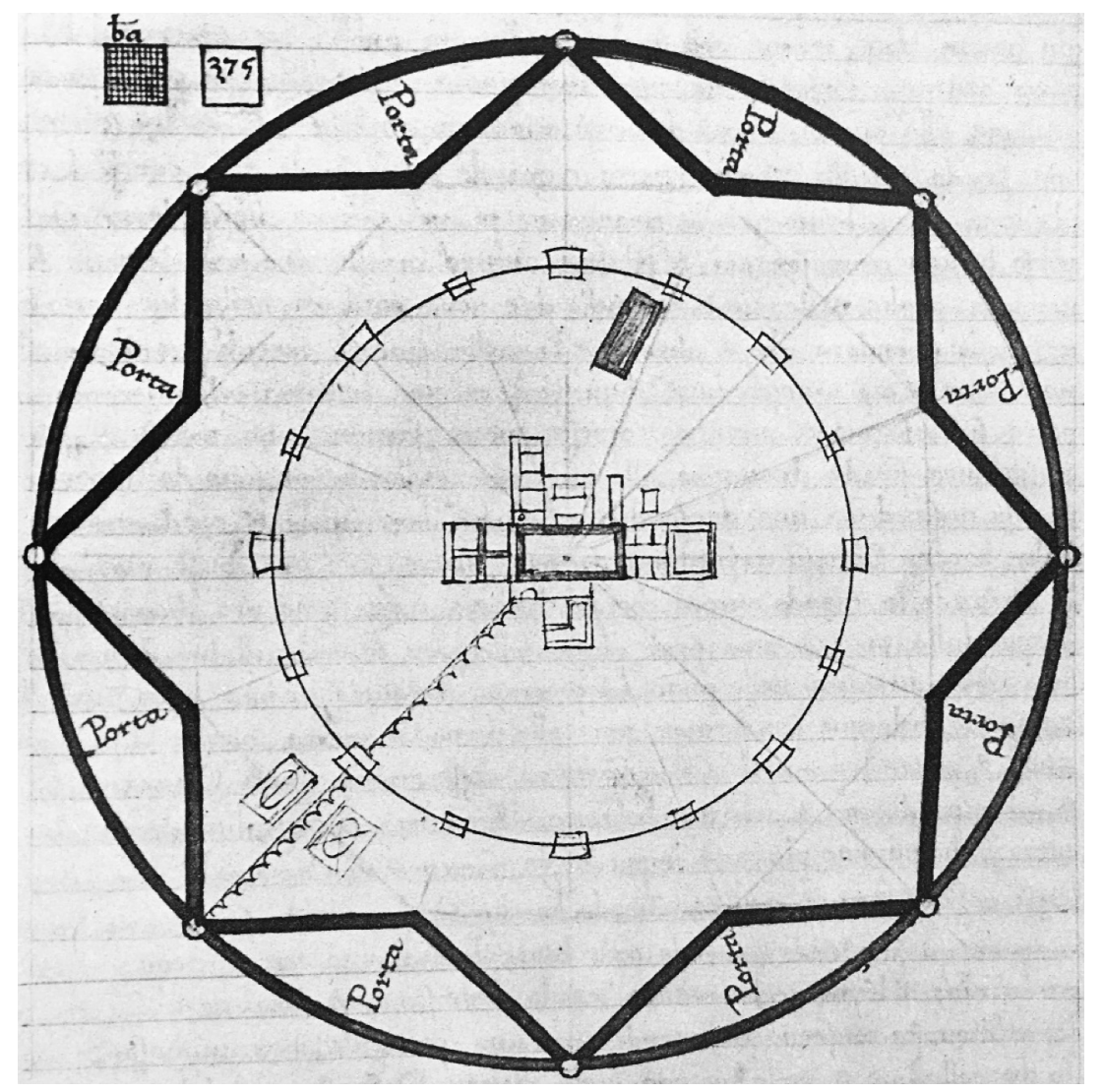

Perante a impossibilidade de implementar a cidade referida, mais tarde, por terras do Egito, teve Dinócrates a autonomia para planear a cidade de Alexandria, cujo modelo conceptual com ruas ortogonais e estrutura hipodâmica, poderá ter funcionado, em parte, como matriz de inspiração para a cidade de Sforzinda (SCHLOSSER, 1984, p. 164). Mesmo existindo inúmeras lacunas e imprecisões nas descrições filaretianas, este assume o processo de construção de uma cidade como algo demorado e complexo, apresentando todo um conjunto de situações tendentes à sua concretização. Sem dúvida que o ambicioso empreendimento de construção de uma cidade com uma dimensão diametral de cerca de $5 \mathrm{~km}$ como aquela a que corresponde a Sforzinda, constitui um notável trabalho de sistematização já que no modo como esta foi formalizada, abarca um conjunto alargado de pontos, que vão desde a construção, à orçamentação, à definição de um modelo organizativo, a problemas de geografia, de urbanismo, que sem dúvida exprimem capacidades ímpares da parte de Filarete.

Tratava-se da disponibilização de um modelo organizativo que já estando sugerido no De re aedificatoria albertiano, Filarete foi o primeiro humanista a efetivar uma proposta desenhada, mesmo que não atinja o fôlego que mais tarde concretiza Francesco di Giorgio. Na realidade o tema da regulação das cidades e a constituição de modelos funcionais organizativos, vai ser assunto, mais tarde, amplamente explorado. Em Sforzinda, Filarete, desenvolve uma forma estrelar composta por 
oito vértices rematados por o mesmo número de torres circulares, alicerçado numa geometria simples de um duplo quadrado rodado $45^{\circ}$ (FILARETE, 1972, pp. 60-64 e pp. 148-178). A configuração utilizada aparenta um desenho simplificado de uma rosa dos ventos que, sendo um exercício académico muito eficaz, corresponde a um excelente ponto de partida para as futuras cidades ideais, desligadas de muitas insuficiências, do caos e das contrariedades das cidades reais. Neste aspeto, o livro filaretiano assume papel inaugural naquilo que será a proposta desenhada de projetos urbanísticos, com forte cariz militar que, a partir do século XVI, possibilitaram todo um processo de regulamentação e de experimentações que potenciaram uma panóplia de possíveis modelos. Mesmo que alguma crítica coloque Sforzinda no plano da utopia, esta teoria só é congruente dado tratar-se de uma conceção idealizada, mas não concretizada. E, provavelmente mesmo não concretizável, já que em rigor o propósito do seu autor é criar atmosfera para uma narrativa simultaneamente épica e fantástica. Se normalmente a utopia existe e se desenvolve no campo literário, também estas cidades - ditas ideais - não conseguem desligar-se do papel, do confinamento da bidimensionalidade do desenho ou do projeto, estando quase sempre muito distantes da realidade (TAVARES, 2014, p. 10).

A descrição de Sforzinda é feita numa base de idealidade, suportada por princípios organizacionais, concretizados através de situações proporcionadas. Ou seja, a questão da medida e da relação controlada entre partes é notoriamente uma situação dominante, que constitui a essência do plano da cidade e dos próprios edifícios ou mesmo dos espaços públicos. Torna-se muito evidente que a geometria enquanto entidade reguladora e disciplinadora das formas, corresponde a um meio privilegiado para o controlo e a concretização das conceções arquitetónicas (POWERS, 2011, pp. 34-35). Na realidade toda esta sistematização e prova de conhecimento atestam aptidões muito desenvolvidas na vertente de arquitetura e de urbanismo. Muito provavelmente, não encontrando outro modo de poder demonstrar estas suas competências, poderá ter sido a escrita fantasiosa um meio eficaz para conseguir que essas habilidades pudessem ser tanto do conhecimento de Sforza como de toda a corte que rodeava o duque.

Não sendo muita a quantidade da obra desenvolvida por Averlino, o seu livro reveste-se de uma importância vital para um melhor entendimento do papel e da importância de homem ligado às artes. De facto, não são conhecidos projetos de edifícios anteriores à sua colaboração com Francesco Sforza, mas naquilo que tem a ver como muitos outras personagens desta época, esta arte - a arquitetura - era o corolário de uma atividade muitas vezes iniciada com outras como a ourivesaria, a pintura ou a escultura, correspondendo a um ponto de evolução e de chegada. Foi assim com Brunelleschi e será, posteriormente, assim com Leonardo da Vinci ou Miguel Ângelo. Nesse sentido, o texto filaretiano, mesmo que enredado de um misto de efabulação e realidade, adquire uma importância primordial para efeitos de perceber algumas das vivências locais e entender muito daquilo que eram os usos e os costumes daquela época.

Curiosamente, os maiores e mais importantes empreendimentos sforzescos em Milão, tiveram todos, em determinado momento, a colaboração de Filarete. Referimo-nos especificamente à catedral de Milão, ao castelo sforzesco (que mereceu o nome de Filarete para o batismo da torre que assinala a entrada principal do recinto) e ao Hospital Maior (cujo modelo planimétrico constitui momento importante, inaugural e incontornável na História da Arquitetura). Na catedral, segundo parece, a colaboração foi muito contida 
Figura 3: Representação do castelo de Milão com Torre de Filarete na parte esquerda, excerto de pintura de Francesco Napoletano (c.1470 - 1501) - Madonna col Bambino. Pinacoteca del Castello Sforzesco, Milão. Fonte: <https:// it.wikipedia.org/wiki/Madonna Lia\#/media/File:Francesco_Napoletano,_MADONNA_LIA,_Milano,_Castello_Sforzesco.jpg> e limitada ao tiburio (TAVARES, 2014, p. 51). Apesar do castelo, desempenhar enorme valor representativo numa cidade como a de Milão e ter sido uma importante aposta de Francesco Sforza, também aqui, os trabalhos terão sido muito contidos e a fatalidade de uma explosão acidental no século XVI terá provocada a irremediável perda da imponente torre, levando à perda de todo o trabalho filaretiano. Somente já no início de século XX e sob projeto de Luca Beltrami, conjugado com amplos trabalhos de reabilitação, se recriou a torre do castelo, adquirindo esta o nome de Filarete, em homenagem ao arquiteto que outrora havia servido dedicadamente o ducado de Milão (FIORIO, 2005).

Mas sem dúvida que a joia da coroa filaretiana é o Hospital Maior de Milão que, pela sua planta cruciforme dupla, desenhando cada quatro pátios e mediada por um pátio monumental retangular, estabilizou uma configuração tipológica que haveria de influenciar múltiplas arquiteturas a jusante (GRASSI, 1972). A qualidade daquela proposta, fez com que, se mantivesse a vontade férrea de um desenho como configuração premiada, apesar de pontualmente ajustada na dimensão da sua zona central e no posicionamento da igreja que seria deslocada do centro gravítico para uma situação mais periférica. Conceptualmente é muito interessante o modo como através da configuração se dividem as enfermarias para crianças abandonadas e mulheres desenhando quatro dos pátios pequenos e as enfermarias para homens, desenhando também outros quatro pátios e garantindo-se assim o princípio de simetria compositiva. Sabendo-se da antipatia demonstrada por Vasari nas suas vites relativamente a Filarete, designadamente quanto à sua qualidade artística, não deixa de ser surpreendente que o mesmo autor, Ihe tenha

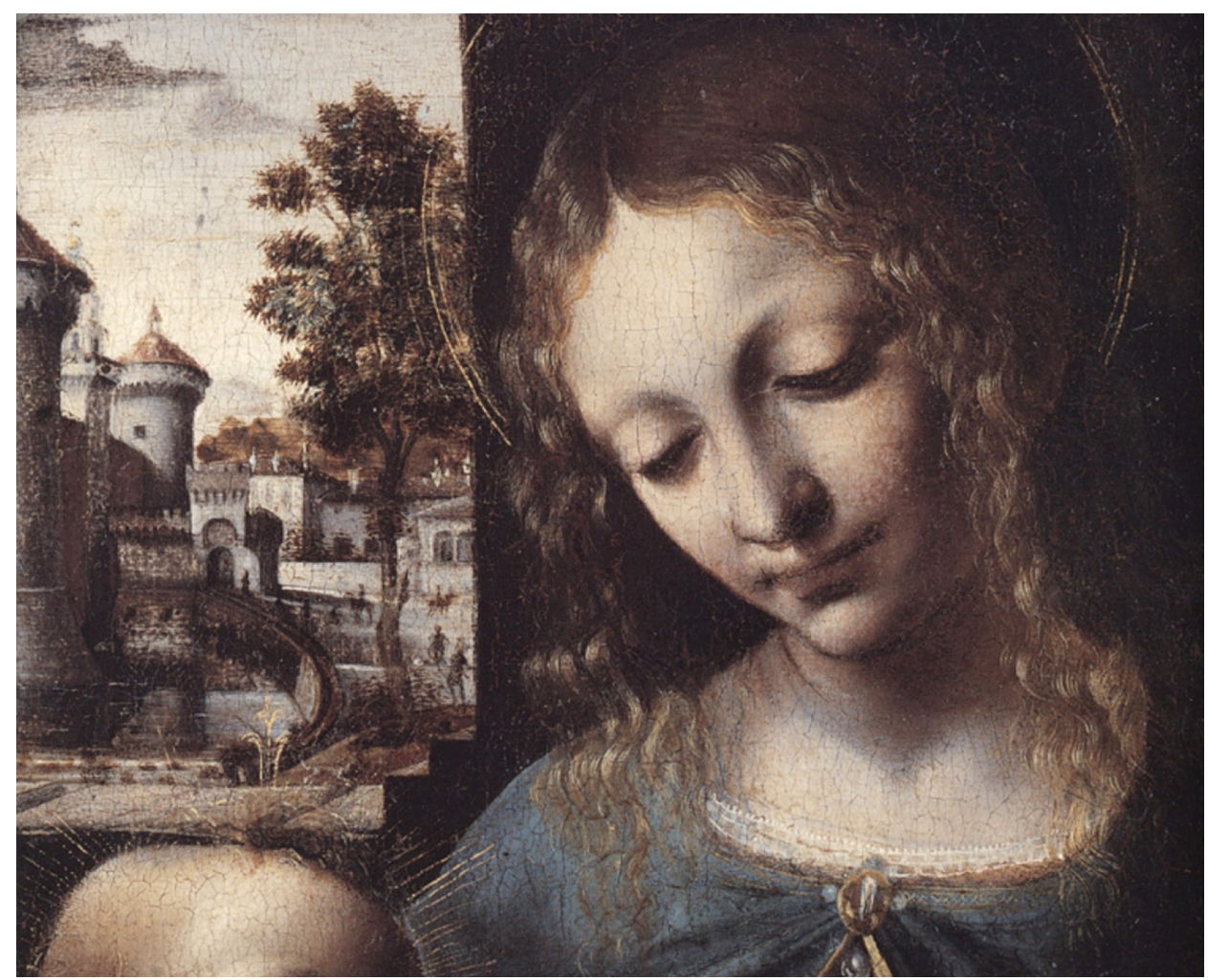


Figura 4: Planta do Hospital de Milão. Fonte: Filarete, Trattato di Architettura, Libro XI, folio 82v. dedicado espaço e inclusivamente, no caso do hospital, tenha enaltecida a sua conceção, dizendo mesmo não existir outro igual em toda a Europa. (VASARI, 1878, p. 456).

Sob o ponto de vista do impacto da obra filaretiana, não é nada desprezível o projeto do Ospedale Maggiore di Milano em termos da história destes equipamentos, como também o desenho idealizado de Sforzinda, que irá ter repercussões quer ao nível das conceções de cidade ideal, como será matriz referenciada nos modelos posteriores de cidades muralhadas com desenho geometrizado. Ambos os exemplos referidos correspondem a elaborações devidamente hierarquizadas e ordenados segundo princípios estáveis e organizados em relação privilegiada entre processo mental e desenho. Nesse aspeto, dada a férrea preocupação com as atividades inerentes à prática arquitetónica, torna-se evidente que Filarete pretende utilizar o subterfúgio de uma escrita romanceada para de modo gradual e consistente ir debitando alguns factos e muitos argumentos que certificam a sua proficiência nesta difícil arte. Esta dinâmica, que abrange múltiplos assuntos, pretendendo dar uma perspetiva de um sujeito multifacetado e informado, acaba por conferir ao texto um caráter enciclopédico (PEDRAZA, 1990, p. 23), ainda que concretizado de modo muito rudimentar. A natureza das múltiplas descrições, claramente enquadradas dentro dos usos e costumes da época, têm servido para o estudo e para um melhor conhecimento daquele tempo.

Mesmo falando de arquitetura, aquilo que emerge no texto filaretiano é sobretudo uma escrita romanceada que na sua génese compatibiliza um discurso com uma imagética. Nesse sentido, mesmo que o enredo não seja suficientemente convincente e absortivo, a utilização do material gráfico é claramente um recurso de arquiteto. Pelo que, muito para além do enredo, o modo como os sucessivos desenhos aparecem como complemento ao texto, dão indícios de que o seu autor sabe do seu valor, da sua capacidade para ensaiar, para pensar e para transmitir pensamentos.

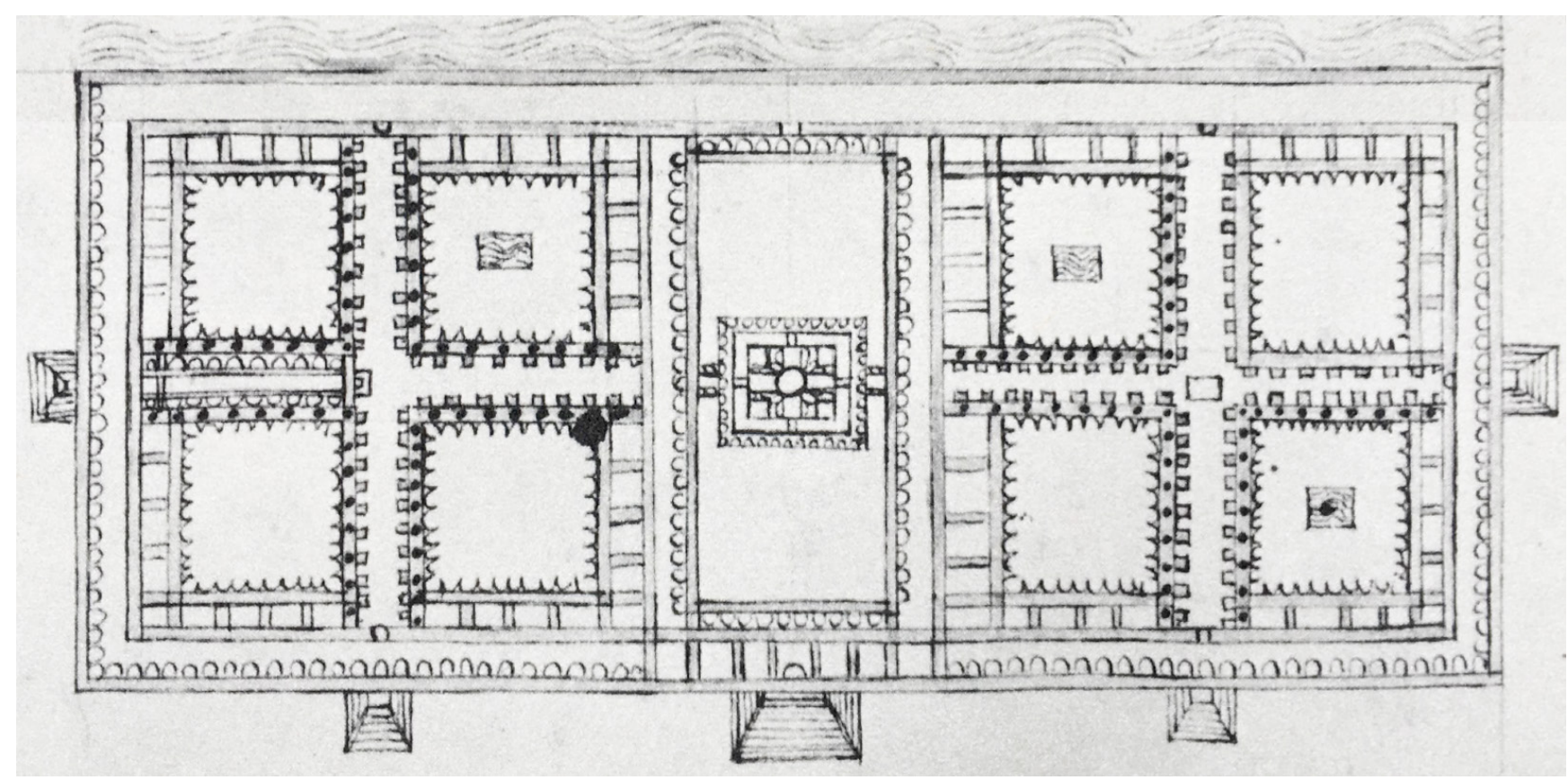


Não parece displicente a circunstância de ser num contexto de decurso de uma refeição que Filarete decide iniciar a sua narrativa. Talvez porque após se terem os estômagos cheios, depois da ingestão de uma qualquer iguaria, se gera atmosfera propensa ao diálogo e ao debate. É mesmo neste ambiente de são convívio que Averlino decide começar o seu romance, aproveitando para colocar o narrador arquiteto em franca e descontraída cavaqueira com alguns membros da sociedade, permitindo antever que naquele contexto os artistas - ou pelo menos certos artistas - conviviam com os mais poderosos, num reconhecimento social dos manipuladores de espaço construído. Naquele contexto, aquele banquete serve simbolicamente para regenerar as energias corporais, mas também é um momento determinante para o estímulo intelectual. Como se sabe, a comida não tem somente um efeito direto sobre o corpo mas exerce muitos benefícios sobre a desempenho da mente (JEANNERET, 1991, pp. 2021). Nesse âmbito, aquele acontecimento, que permitia momentos alternados entre conversas triviais e assuntos sérios foi escolhido por Filarete para poder, naquele contexto, dar nota da sua total integração social e cumulativamente deixar lastro do seu conhecimento. E, ao começar o seu livro com este registo, o seu autor pretende deixar posição lapidar sobre o seu posicionamento social e sobre a sua autoridade nas matérias da arquitetura.

Sabemos, contudo, que a estrutura narrativa do libro architettonico não é particularmente elaborada e o modo como o enredo se desenvolve não indicia a existência de um guião suficientemente meditado. Se este último existiu, quase de certeza que não foi cumprido ou, então, houve perda irreparável de conteúdos. O texto foi elaborado, na sua maior parte, pressupondo uma lógica de interação entre um arquiteto e o seu príncipe. Uma situação que por analogia pode aproximá-lo de Platão na lógica do recurso literário ao diálogo como método cativante de apresentação de argumentos e de contraposição de ideias. Ainda sob uma influência platónica poderá ter sido o desenvolvimento da ideia do arquiteto enquanto ser que imita as construções divinas, que acresce ainda a circunstância de descrição da criação das cidades de Sforzinda e de Plusiapolis ou então na tentativa de caracterização de um modelo organizativo de uma cidade idealizada. Segundo Onians (1971, p. 105), Filarete poderá ter sido influenciado, principalmente por três textos de Platão, designadamente o Timeu, o Crítias e as Leis; o primeiro na referência da criação divina do universo e do homem à sua imagem, o segundo na descrição de duas cidades - Atenas e Atlântida - e do seu modelo organizacional e o terceiro na definição de cidade ideal.

Apesar dos textos platónicos só estarem disponíveis na língua grega, sabe-se que Averlino era amigo de Filelfo, com ímpar domínio desta língua e justificação suficiente para quando, no contexto da narrativa filaretiana, surgiu um texto em helénico ser solicitada a colaboração de Iscofrance Notilento (anagrama de Francesco de Tolentino, conhecido como Filelfo) para decifrar corretamente o escrito (ONIONS, 1988, pp. 159-160). (Figura 4) A descoberta desse texto - denominado Livro de Ouro -, que curiosamente também apresenta ilustrações, acontece no contexto da abertura dos caboucos para a fundação do porto de Sforzinda, cujo conteúdo remete para tempos remotos. Dentro dessa narrativa, no seguimento da exploração dos conteúdos daquele volume, consta a descrição de uma fantástica torre, curiosamente bem detalhado sobre o ponto de vista iconográfico, complementada por desenhos e da autoria de Onitoan Nolievra (FILARETE, 1972, p. 663), que mais não é o do que um anagrama de Antonio Averlino. 


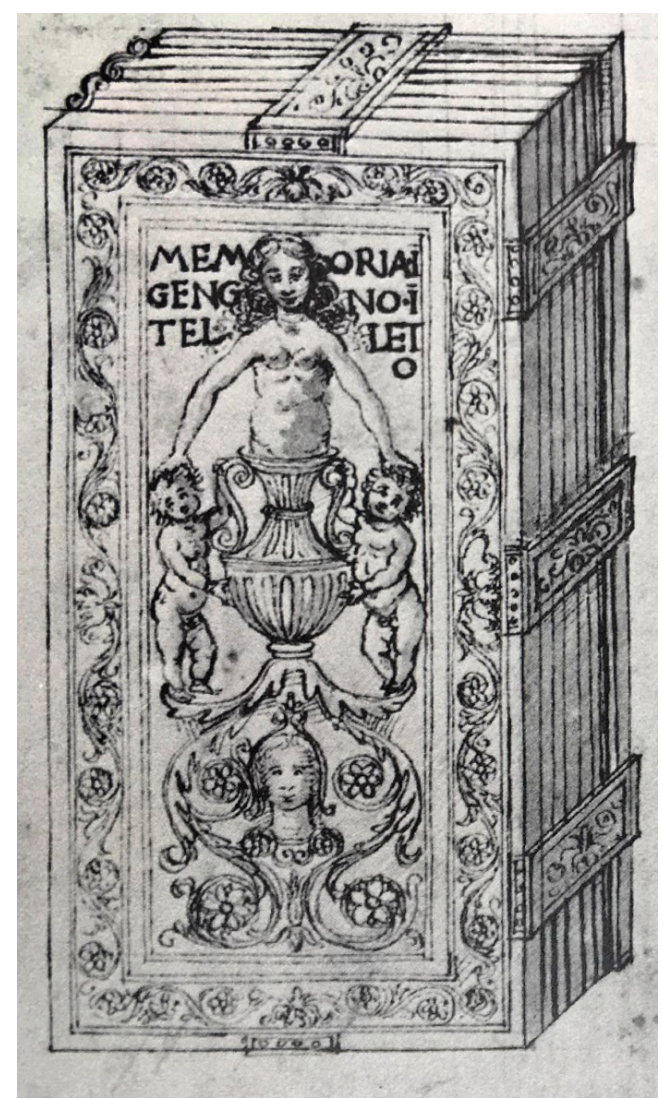

Figura 5: Livro de Ouro. Fonte: Filarete, Trattato di Architettura, Libro XIV, folio 108v.
O livro de Filarete apresenta uma escrita que, sistematicamente, pretende ser descritiva e se concretiza sob a forma de construção de uma história que nalguns aspetos parece ter sido desenhada e preparada para ser ouvida. Se o livro tem todo um cariz formativo e didático, em boa verdade, também apresenta momentos apoteóticos muito elaborados sob o ponto de vista imagético e sensorial, remetendo para circunstâncias que transcendem o mero horizonte literário e que eventualmente correspondem a uma tentativa de criar localmente uma determinada atmosfera ou algum suspense perante uma hipotética audiência. O contexto em que aquela publicação foi orquestrada, denota não ter sido desenvolvida existindo uma premissa da possibilidade de um modelo tipográfico, havendo contudo a vontade de cobrir e alargar públicos, pelo que terá todo o sentido que este texto possa ter tido uma abordagem que passasse mesmo por um processo auditivo, onde houvesse um leitor e uma assembleia que em contexto particular ouvisse atentamente aquela empolgante narrativa (ENGINSON,2002). Nada melhor para prender a atenção de leitores e ouvintes do que a caracterização de alguns cultos, de determinados presságios, auxiliando na escolha da localização dos edifícios ou para a perceção de alguns factos extraordinários que através de leitura simbólica ajudavam a legitimar escolhas e a certificar procedimentos. Neste contexto, muito do que acontece respeita a princípios astrológicos que transformam qualquer acontecimento como sendo um assunto sujeito a consideração realizada por entidade superior ou divinatória. Por exemplo, aquando da cerimónia da fundação da cidade 
de Sforzinda, é descrito um episódio envolvendo separadamente uma serpente e uma águia, cujas participações, naquele contexto, são encaradas, no livro, como presságios e acontecimentos que certamente podem simbolizar outros significados, mas também serem diretamente relacionados com algumas imagens da época (FILARETE, 1972, pp. 108-110). Refira-se que, explicitamente, o brasão de adotado por Francesco Sforza era composto, na sua parte central por duas serpentes e duas águias organizadas em quadrado e repetidas na diagonal.

Apesar das diversas imagens construídas, para Filarete, a arquitetura é para ele um tema sério que se constrói sobre inúmeros saberes e sobre uma sólida formação literária que, tal como havia anunciado Vitrúvio (2006, p. 31), deve cobrir uma amplitude de áreas, tais como Desenho, Geometria, Astrologia, Aritmética, Filosofia, Música, Retórica, Medicina, Direito ou História (FILARETE, 1972, p. 428). Neste domínio o autor denota haver lido com atenção o texto vitruviano, havendo uma notória sobreposição argumentativa, que na sua génese legitima um conhecimento mais detalhado do tratado do arquiteto romano. No caso, Filarete, fazendo o apogeu do domínio de toda uma teoria que seria certamente o garante da sua competência, resume-se a considerações bastante genéricas que conduzem a divagações sistemáticas entre o deslumbramento pelo futuro e a nostalgia pelo passado, dando nota evidente de alguma dissonância com o seu tempo presente naquele contexto. A valorização da arquitetura antiga está normalmente a reboque de uma ação de nostalgia de um tempo passado, cuja realidade era ainda pouco conhecida, havendo ainda uma espécie de idealização fantástica que de algum modo se sobrepunha a qualquer tentativa de conhecimento através da arqueologia ou de estudo apurado de textos descritivos de época (PEDRAZA, 1990, p. 19).

Como espaço, a cidade é notoriamente o meio mais seguro, o eleito para os homens viverem e conviverem. Para efeitos de arquitetura, o espaço urbano é o meio preferencial para esta disciplina se poder desenvolver oferecendo todo um conjunto vasto de programas que têm como missão a satisfação de necessidades dos homens. Sob o pretexto de Sforzinda, é percorrido todo um vasto leque de edifícios que responderiam a programas de época e que através, quer de desenhos organizativos quer de descrições sumárias, é dada nota de capacidade para desenvolver projeto funcional de raiz. Como novidade, aparece o ambicioso processo de relacionar a arquitetura com o espaço urbano adjacente, de precisar que para além do edifício, a arquitetura começa na conceção integral da cidade. A boa arquitetura não se resume à imagética de um qualquer edifício, é uma aposta integrada que respeita e se apresenta a partir de uma coerência de conjunto, sendo, por isso, a resposta adequada na sua dimensão urbanística e funcional.

A centralidade do discurso que é alicerçada numa premissa de que a arquitetura resulta de compromisso entre encomendante e arquiteto, irá tender para uma sucessiva apresentação de várias tipologias que, respeitando um modelo conceptual, vão permitir organizar a cidade. E, se sempre foi claro o papel preponderante do dono de obra ao nível do desenvolvimento de uma qualquer proposta e sobretudo o seu poder decisório relativamente às soluções implementadas, Filarete procede a uma objetiva sobrevalorização do projeto intelectual desenvolvido pelos arquitetos. No caso concreto, são estabelecidas algumas analogias que colocam a figura do arquiteto e do príncipe em situação de quase igualdade, correspondendo o primeiro à mãe e o segundo ao pai, sendo o edifício o resultado dessa profícua relação: o filho. Este princípio de semelhanças, permite também estabelecer relação entre o tempo necessário para o 
Figura 6: Representação de Adão. Fonte: Filarete, Trattato di Architettura, Libro I, folio 4v. estudo e desenvolvimento do projeto, colocado em paridade com o tempo de gestação de um bebé no útero feminino. Esta descrição, sem dúvida que corresponde a um enorme progresso naquilo que será no futuro o papel dos arquitetos no processo de elaboração dos projetos e de concretização das arquiteturas. Um exercício profissional, amplamente dignificado e respeitado, que conjuga artisticidade com ciência, muito sustentado em princípios reguladores, antropométricos e construtivos. Um papel que envolve teoria e prática, que se resolve com inteligência, com domínio sobre as medidas e sobretudo pela pesquisa em desenho, permitindo dar consistência e robustez à antevisão proporcionada pelo projeto. Precisamente no mesmo contexto, Averlino reforça, ainda, o papel do arquiteto no contexto da obra e da sua importância para efeitos de controlo de custos e de qualidade da construção (FILARETE, 1972, pp. 39-44). No processo de desenvolvimento do projeto, é muito importante o caráter conceptual do desenho e da geometria, já que estas disciplinas adquirem aí um papel preponderante. Para além de meio preferencial de expressão, pelas suas características, estas disciplinas, fornecem um meio assético e muito potente em arquitetura. Na realidade, os operadores gráficos disponibilizados através do desenho possibilitam um meio muito económico e prático para as simulações e para as confrontações com o real.

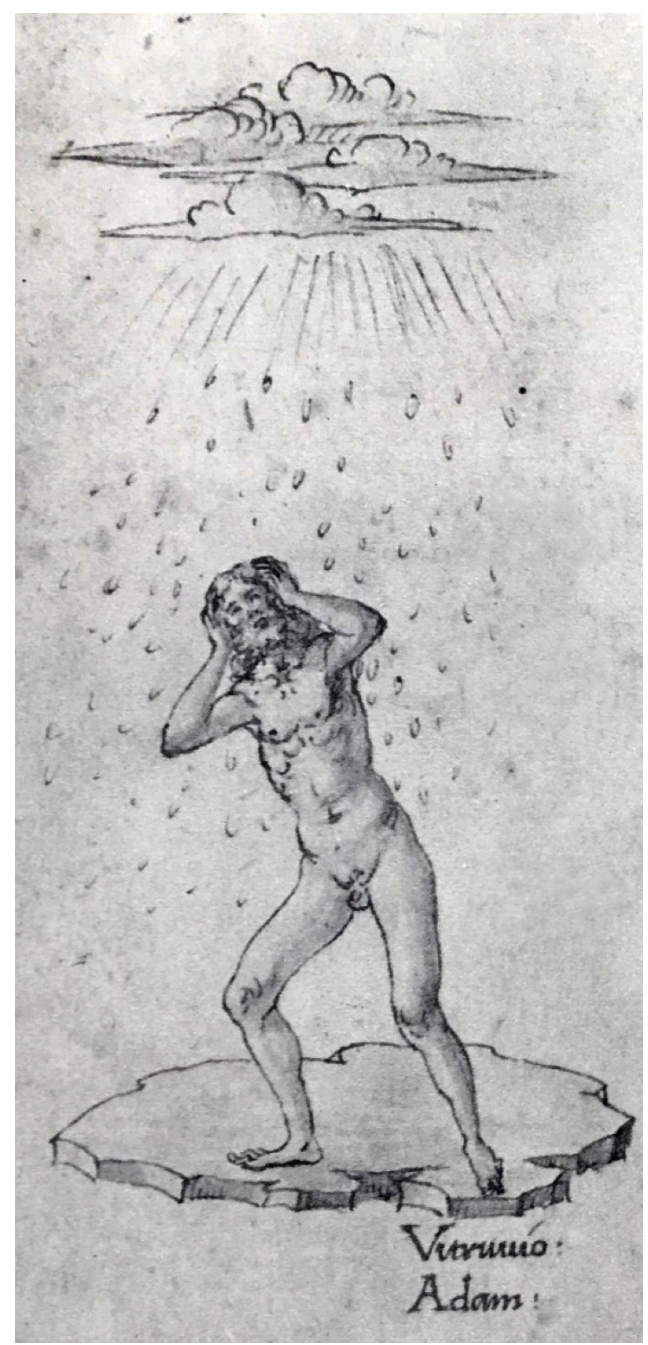


No contexto do Renascimento, a representação e os modos de a concretizar adquirem um enorme valor estratégico e operativo. Existindo um meio seguro e eficaz para conseguir a reprodução gráfica da realidade de maneira a que, protocolarmente, essa concretização pudesse ser encarada como uma espécie de cópia, com características transformativas, era claramente tanto um desígnio como uma necessidade. No campo da arte, o recurso ao desenho rigoroso era uma ambição que possibilitaria um instrumento seguro de inquirição e de validação. A utilização de métodos geométricos rigorosos foi inequivocamente uma conquista que favoreceu a experimentação do espaço conceptual, ajudando todo o processo intelectual de criação das obras de arte.

Será necessário, sobretudo muita elasticidade mental para conciliar as visões nostálgicas do passado com a esperança de um futuro que se quer promissor. Filarete promove a arte em geral e a arquitetura em particular como uma atividade de enorme valor cultural que, pelas emoções que transporta e pelo seu intrínseco significado e valor, colocam os seus executantes como operadores privilegiados no contexto de uma qualquer civilização.

Para além de questões estruturais da cidade e das suas arquiteturas, Averlino reflete sobre as origens da própria arquitetura. Nesse sentido é explicitado a relação fundacional entre a arquitetura e o processo evolutivo do homem e a sua necessidade de abrigo. Este é um tema que foi abundantemente tratado pela história da arquitetura, mas tem muito provavelmente a sua génese no tratado vitruviano. (VITRÚVIO, 2006, pp. 71-73). Acoplado a esse facto são descritas, em paridade, as necessidades e implementações de abrigos até chegar à habitação enquanto espaço de vivência e de interação social. Pelo exposto, reveste particular importância o arquétipo da cabana concretizado com a ideologia cristã através da referência explícita a Adão, por Filarete, enquanto primeiro ser da humanidade e, inevitavelmente, como ser fundador da arquitetura. Esta referência é certamente um testemunho eficaz do esforço filaretiano de conciliação do universo clássico com o mundo medieval, que depois se vai reconhecer naquilo que serão os princípios de sublimação das capacidades dos homens e que nortearão o humanismo mais pujante. No mesmo contexto, no Livro I e no início do Livro II de Averlino é desenvolvida uma analogia antropomórfica em redor da arquitetura, estabelecendo recorrente proximidade argumentativa a Vitrúvio. O que queremos dizer é que a aceitação de todo uma dinâmica fundada em princípios e normas bíblicas, vai cruzar-se com uma conceção mais humanizada do mundo que encara o tempo histórico clássico como uma inspiração para colocar no centro nevrálgico dos acontecimentos uma dimensão iluminada por princípios e por valores construídos a partir dos dados reais e sensoriais. Esta compatibilização de espaços, historicamente diferenciados, transforma toda a atmosfera narrativa num contexto nevrálgico de apologia de uma atmosfera que sistematicamente se desloca entre a realidade próxima e a efabulação.

\section{Conclusão}

Quiseram as contingências da vida que Antonio Averlino não tivesse conseguido, profissionalmente, um desempenho tão grandioso como aquele que de modo legítimo deve ter ambicionado. Assim aquilo que, apesar de todas as circunstâncias inerentes ao seu percurso, constituiu uma das grandes heranças filaretianas, foi o seu denominado tratado de arquitetura. Este registo, mais do que um texto exemplar, 
normativo, histórico ou formativo, correspondia a uma efabulação registada segundo uma cadência irregular e nem sempre congruente. Na realidade, aquele texto, o tal libro architettonico, era uma mescla de memórias polvilhadas por resquícios de realidade, segundo alguma imaginação que pretendia dar corpo a uma existência que mereceria um desenlace muito mais épico.

O libro architettonico de Averlino, muito longe de se constituir como um tratado, desempenha a notável função de um romance fundado em muitos dados biográficos que, pela sua riqueza descritiva, ajudam a perceber o desempenho e as agruras de um arquiteto competente e determinado. Nesse âmbito importa olhar para o texto de Filarete como uma narração formada por um misto de ficção e de realidade que presta um notável serviço à arquitetura. Reconhecendo-se um caráter publicitário e panfletista do livro, cumprindo-se assim o desígnio de evidenciar a personalidade de Filarete, este escrito acaba por deixar muito explícito aquilo que será a importância e o desempenho dos arquitetos ao nível da organização e da produção tanto de edifícios como dos espaços urbanos adjacentes. De facto, apropriando-se do nome que poderia induzir a um texto que tratasse de modo consistente e em profundidade a arte e a ciência da arquitetura, o livro somente aflora os aspetos mais normativos ou manualísticos, focando aspetos do quotidiano, deixando transparecer situações de vivências normais, polvilhadas com uma boa dose de imaginação, possibilitando a intencional valorização de todo um trabalho que sem aquele testemunho correria fortes hipóteses de ser esquecido. E, para dar credibilidade e sobretudo acrescentar valor àquela estada de Averlino em Milão, torna-se pertinente, quase imperativo, que seja adoçado o contributo do arquiteto florentino através de uma dose de efabulação que coloca todo aquele trabalho num patamar mais elevado e com muito maior tenacidade.

No seu tratado, Filarete constrói toda uma narrativa que vive do facto histórico e de conteúdos parcialmente inventados, convergindo para um enredo que tanto esboça atos de quotidiano como empolgantes feitos que ajudam a sublimar um determinado contexto e algumas personalidades. Provavelmente, são todas estas dinâmicas, todos os gloriosos acontecimentos, que sustentam a potencial verosimilitude de conteúdos, que pintam todo uma realidade, que fantasiam e inventam episódios que não coincidindo com atos da vida quotidiano, bem o poderiam ser. Pela sua estrutura, pelo seu enredo, pelos seus conteúdos, é apresentado um livro arquitetónico que é mesmo, somente, um convincente pretexto para espraiar uma escrita fantasiada que mormente corresponde a um verdadeiro romance.

Trata-se de um texto ficcionado que ajudou a resgatar um arquiteto do registo das existências mais anónimas e que, com isso, deixou pistas e dados seguros que ainda hoje ajudam a reescrever a história e que se apresentam como sementes para melhor interpretar tempos passados. O livro arquitetónico de Filarete, na sua essência, não constitui, nem se pretende que venha a constituir, um texto escrito para especialistas, não adquirindo por isso um valor formativo, mas antes apresenta-se como vocacionado para ser lido por ou para audiências mais abrangentes, apresentando características mais informativas. Nesse sentido e atendendo a este público, naturalmente, o seu conteúdo, o seu enredo, foi orientado para áreas de menor tecnicidade.

Concomitantemente, o tratado serve audiências interessadas e suscetíveis a motivos de sedução suplementares, para que além da informação existente, houvesse uma 
densidade imaginativa que conduzisse a um acutilante interesse de leitura. E, Filarete, percebeu que não tendo um saber tão vasto como o provarem ter outros seus antepassados ou contemporâneos, o melhor caminho para assegurar o futuro da sua experiência através de um escrito era ensaiar a via do romance e da ficção.

Por princípio, a arquitetura deu a Filarete a possibilidade de se aperceber da necessária coerência entre forma e construção ao serviço dos homens, mas e seu exercício intelectual convertido em livro deu-lhe o ensejo de que esse ficcionado trabalho o poderia projetar para a eternidade.

\section{Referências bibliográficas}

ALBERTI, Leon Battista. Da Arte Edificatória. Lisboa: Fundação Calouste Gulbenkian, 2011.

BARNES, Carl F.. The Portfolio of Villard de Honnecourt. Burlington: Ashgate Publishing, 2009.

BECHMANN, Roland. Villard de Honnecourt, La pensée technique au XIlle siècle et sa communication. Paris: Picard Éditeur, 1991.

CAVALLERO, Daniela Gallavotti. La Basilica del Rinascimento. In: PIETRANGELI, Carlo. La Basilica di San Giovanni in Laterano a Roma. Florença: Nardini Editore, 1990.

CERVERA VERA, Luís. El Códice de Vitrúvio Hasta sus Primeras Versiones Impresas. Madrid: Real Academia de belas Artes de San Fernando, 1978.

CRESSON, André. Aristóteles. Lisboa: Edições 70, 1988.

ECO, Umberto. From the Tree to the Labyrinth. Cambridge: Harvard University Press, 2014.

ENGINSON, Ayse Sevil. The Visuality/Aurality of Filarete's Treatise on Architecture. Nova lorque: Cornell University, 2002.

FARBAKY, Péter. II Ruolo dela Teoria e dela Prassi dell'Architettura Rinascimentale nela Rapresentanza del Potere di Mattia Corvino. In: FARBAKY, Péter et alii. Mattia Corvino e Firenze. Florença: Giunte Editore, 2013.

FILARETE, Antonio Averlino detto il. Trattato di Architettura. Milão: Edizioni il Polifilo, 1972.

FIORIO, Maria Teresa. // Castello Sforzesco di Milano. Genebra-Milão: Skira editore, 2005.

GRASSI, Liliana. Lo Spedale di Poveri del Filarete. Milão: Università degli Studi di Milano, 1972.

MACIEL Manuel Justino. Introdução. In: Vitrúvio. Tratado de Arquitetura. Lisboa: IST Press, 2006.

MCEWEN, Ingra Kagis. Vitruvius, Writing the Body of Architecture. Cambridge: The MIT Press, 2003.

MERRIL, Elizabeth M.. The Trattato as Textbook: Francesco di Giorgio's Vision for the Renaissance Architect. Architectural Histories, 1 (1): 20, 2013.

MURTINHO, Vítor. Alberti e Filarete: Da Perspetiva à Cidade Ideal. In: KRÜGER, Mário et alii. Na Génese das Racionalidades Modernas II. Coimbra: Imprensa da Universidade de Coimbra, 2015.

MUNTZ, Eugène. Les mésaventures du sculpteur-architecte Filarete, 1448-1449, Courrier de I'Art, n' 3, 1883 .

ONIONS, John. Alberti and Filarete. A study in heir sources. Journal of the Warburg and Courtauld Institutes, vol. 34, 1971.

ONIONS, John. Bearers of Meaning. Cambridge: Cambridge University Press, 1988. 
PEDRAZA, Pilar. Introduccion. In: FILARETE, António Averlino. Tratado de Arquitetura. VitoriaGasteiz: Ephialte, Instituto de Estúdios Iconográficos, 1990.

PELLEGRIN, Élisabetth. La Bibliothèque des Visconti et des Sforza. Paris: Centre National de la Recherche Scientifique, 1955.

POWERS, Jonathan. Building Utopia: The status of the Ideal in Filarete's Trattato. In: Imagining and Making the World. Oxford: Peter Lang, 2011.

SALMI, Mario. Proluzione. Arte Lombarda, n³8/39, 1973.

SCHLOSSER, Julius Von. La Littérature Artistique. Paris: Flammarion, 1984.

SCHULTZ, Juergen. Book review: Filarete, Treatise on Architecture, trans. J. Spencer, New Haven, 1965, 2 vols. Journal of Aesthetics and Art Criticism 25, 1967.

TAVARES, Domingos. Antonio Averlino Filarete, a Cidade Ideal. Porto: Dafne Editora, 2014.

VASARI, Giorgio. Le vite de' piu eccellenti pittori scultori ed architettori (1568), Tomo II, Florença: Sansoni Editori, 1878.

VITRÚVIO. Tratado de Arquitetura. Lisboa: IST Press, 2006.

WIEBSON, Dora. Los Tratados de la Arquitetura, de Alberti a Ledoux. Madrid: Hermann Blume, 1988. 